\title{
Targeting Enox1 in tumor stroma increases the efficacy of fractionated radiotherapy
}

\author{
Clayton A. Smith ${ }^{1,2}$, Stacey Mont ${ }^{1}$, Geri Traver ${ }^{1}$, Konjeti R. Sekhar ${ }^{1}$, Peter A. Crooks ${ }^{3}$, \\ Michael L. Freeman ${ }^{1}$ \\ ${ }^{1}$ Department of Radiation Oncology, Vanderbilt University Medical Center, Nashville, TN 37232, USA \\ ${ }^{2}$ Current Address: Department of Radiation Oncology, Mitchell Cancer Institute, University of South Alabama, Mobile, \\ AL 36604, USA \\ ${ }^{3}$ Department of Pharmaceutical Sciences, College of Pharmacy, University of Arkansas for Medical Sciences, Little Rock, \\ AR 72205, USA \\ Correspondence to: Clayton A. Smith, email: claytonsmith@health.southalabama.edu \\ Michael L. Freeman, email: michael.freeman@vanderbilt.edu \\ Keywords: radiation therapy, Enoxl, xenograft, tumor stroma, endothelial \\ Received: June 07, $2016 \quad$ Accepted: October 14, $2016 \quad$ Published: October 24, 2016
}

\section{ABSTRACT}

The goal of this investigation was to clarify the question of whether targeting Enox1 in tumor stroma would synergistically enhance the survival of tumor-bearing mice treated with fractionated radiotherapy. Enox1, a NADH oxidase, is expressed in tumor vasculature and stroma. However, it is not expressed in many tumor types, including HT-29 colorectal carcinoma cells. Pharmacological inhibition of Enox1 in endothelial cells inhibited repair of DNA double strand breaks, as measured by YH2AX and 53BP1 foci formation, as well as neutral comet assays. For 4 consecutive days athymic mice bearing HT-29 hindlimb xenografts were injected with a small molecule inhibitor of Enox1 or solvent control. Tumors were then administered 2 Gy of $x$-rays. On day 5 tumors were administered a single 'top-up' fraction of $30 \mathrm{~Gy}$, the purpose of which was to amplify intrinsic differences in the radiation fractionation regimen produced by Enox1 targeting. Pharmacological targeting of Enox1 resulted in $80 \%$ of the tumor-bearing mice surviving at 90 days compared to only $\mathbf{4 0 \%}$ of tumor-bearing mice treated with solvent control. The increase in survival was not a consequence of reoxygenation, as measured by pimonidazole immunostaining. These results are interpreted to indicate that targeting of Enox1 in tumor stroma significantly enhances the effectiveness of 2 Gy fractionated radiotherapy and identifies Enox1 as a potential therapeutic target.

\section{INTRODUCTION}

Radiation therapy, an important therapeutic modality for the treatment of cancer, is used to treat approximately $50 \%$ of cancer patients [1] for the purposes of localregional control of invasive disease, to reduce the risk of metastases, and for palliation [2]. Current technology allows precise 3-dimensional irradiation of tumors that yields significant sparing of normal tissue. Yet even with this outstanding ability to selectively target tumor tissue, there are many instances in which tumors do not respond to radiation. Additionally, patients whose irradiated tumors recur following an initial response experience a significant reduction in median overall survival $[3,4]$. The failure of radiation therapy to yield definitive, local-regional control in subsets of patients underscores the need for development of new therapeutic strategies.

Enox 1 is a NADH oxidase $[5,6]$ that is expressed in endothelial and other cell types $[6,7]$. Morpholino and pharmacological targeting of Enox1 in a zebrafish model of embryogenesis revealed that Enox 1 is required for vascular development [6]. RNAi and small molecule targeting of Enox 1 were shown to inhibit migration of human and mouse endothelial cells and the ability of these cells to form tubule-like structures in matrigel, as well as to suppress neo-angiogenesis driven by growth of Lewis Lung Carcinoma tumor cells in a dorsal skin fold vascular window chamber [8]. Additionally, pharmacological or RNAi-mediated targeting of Enox1 enhances endothelial cell susceptibility to the cytotoxic effects of ionizing 
radiation [8]. Thus, there is congruence between genetic approaches and small molecule inhibition with regard to inhibiting angiogenesis and the radiation response of endothelial cells. Multi-fractionation irradiation of allograft and xenograft tumors was found to synergize with pharmacological targeting of Enox 1 to reduce tumor microvascular density and decrease tumor growth [8]. Thus, Enox 1 enzymatic activity links NADH metabolism to both angiogenesis and the survival of endothelial cells following DNA damage produced by ionizing radiation.

The question of whether targeting of tumor stroma synergistically contributes to tumor control following fractionated radiotherapy represents a fundamental, unresolved question. The 'top-up' experimental approach was developed in order to amplify and detect intrinsic differences in radiation fractionation regimens [9]. Several small, clinically relevant doses of radiation are administered, which are then followed by a very large single dose that amplifies the effect of each fraction $[9,10]$. Using this approach we investigated the question of whether concurrent $\mathrm{x}$-irradiation and pharmacological inhibition of Enox 1 in tumor stroma could increase the survival of HT29 tumor-bearing mice. The HT-29 tumor model was used because these cells do not express Enox 1 and they are not radiosensitized by pharmacological inhibition of Enox1.

Herein, we report that pharmacological targeting of Enox1 inhibits DNA double strand break repair in endothelial cells and is one plausible mechanism for Enox1-mediated radiosensitization. To address the question of whether the survival of tumor-bearing mice could be increased by Enox1 targeting in tumor stroma during fractionated radiation therapy, HT-29 xenografts were administered 2 Gy x 4 q.d. in the absence or presence of an Enox 1 small molecule inhibitor. On day 5 tumors were given a 'top-up' dose of 30 Gy. Targeting of Enox 1 in tumor stroma increased survival of tumor-bearing mice 2 fold when measured 90 days after irradiation. This increase in survival, from $40 \%$ to $80 \%$, was independent of the tumor's hypoxic fraction, as quantified by the hypoxic marker pimonidazole. We interpret these results to indicate that targeting Enox1 in tumor stroma concurrently with radiotherapy can provide a survival advantage.

\section{RESULTS}

\section{Suppression of the NADH oxidase, Enox1}

The activity of the NADH oxidase Enox 1 is required for intracellular regulation of nicotinamide adenine dinucleotide homoeostasis. The enzyme catalyzes the following reaction: $2 \mathrm{NADH}+\mathrm{O}_{2}+2 \mathrm{H}^{+} \rightarrow 2 \mathrm{NAD}^{+}+$ $2 \mathrm{H}_{2} \mathrm{O}$ [5]. Genetic or pharmacological inhibition of Enox 1 has been shown to significantly increase intracellular NADH levels $[6,11]$. Thus, it was of interest to determine if Enox1 inhibition would impact nicotinamide adenine dinucleotide-dependent metabolism.
Poly (ADP-Ribose) Polymerase 1, (PARP1) catalyzes poly(ADP-ribosyl)ation of proteins in a NAD ${ }^{+}$ dependent reaction and thus PARP1 activity is a useful surrogate marker for NAD+ metabolism. We used two independent Enox 1 shRNAs expressed from retrovirus to suppress expression of Enox1 and then investigated PARP1 activity using a well characterized assay [12] (Figure 1a). Enox1 expression was completely suppressed 48 hrs after shRNA targeting, as was PARP1 activity. Cells respond to radiation-induced DNA strand breaks with rapid PARP1-dependent poly(ADP-ribosyl)ation. However, a $3 \mathrm{hr}$ exposure to VJ115, ((Z)- $( \pm)-2-(1-$ benzylindol-3ylmethylene)-1-azabicyclo[2.2.2] octan-3-ol), a small molecule Enox 1 inhibitor [8], suppressed radiation-induced PARP1 activity (Figure 1b). The basal poly(ADP-ribosyl) ation that was observed during the $3 \mathrm{hr}$ VJ115 exposure may be a consequence of incomplete NAD+ depletion.

VJ115-mediated suppression of poly(ADP-ribosyl) ation was not a consequence of direct inhibition of PARP1 activity (Figure 1c). The activity of purified recombinant PARP1 measured in the presence of exogenous NAD+ was quantified in the absence or presence of the specific PARP1 inhibitor 3-aminobenzamide (3-AB) or VJ115. As shown in Figure 1c, 3-aminobenzamide produced concentration-dependent PARP1 inhibition relative to control activity $(P<0.05)$ whereas VJ115 did not produce inhibition $(P>0.05)$. Rather a small degree of enhanced activity (on the order of $25 \%$ ) was observed. The reason is not currently understood. Taken together (Figure 1 and refs $[6,11])$ the results indicate that targeting of Enox 1 can deregulate nicotinamide adenine dinucleotide homeostasis.

\section{Enox1 and the radiation response}

Although pharmacological and RNAi-mediated targeting of Enox 1 increases endothelial cell radiosensitivity [8] as measured by colony formation assays, it is not known if this is a consequence of inhibition of the DNA damage response. Exposure to 1.5 Gy of $\mathrm{x}$ or $\gamma$-irradiation generates more than 1000 damaged bases, at least 1000 single strand DNA breaks, and 40 double strand breaks in a mammalian cell [13]. NAD+/NADH homeostasis represents a critical node for a cell's response to DNA damage [14]. Therefore we next determined whether targeting of Enox1 would affect repair of DNA damage. Human umbilical vein endothelial cells (HUVECs) were exposed to solvent control (DMSO) or $50 \mu \mathrm{M}$ VJ115 for $3 \mathrm{hrs}$ prior to, during, and for $3 \mathrm{hrs}$ after irradiation. Previously, Enox 1 was partially purified from HUVECs and using ENOX1 enzymatic activity assays we determined that the $\mathrm{EC}_{50}$ for $\mathrm{VJ} 115$ was $10 \mu \mathrm{M}$. We chose to use $50 \mu \mathrm{M}$ in our cell culture assays in order to completely inhibit enzymatic activity. The resulting survival curves were best fit by the equation $S=1-\left(1-\mathrm{e}^{-\mathrm{D} / \mathrm{Do})}\right)^{\mathrm{n}}[15]$. For the DMSO control survival curve, $\mathrm{D}_{\mathrm{o}}=2.1$ and $\mathrm{n}=1.7$, (Figure 2a). Exposure to VJ115 decreased the $\mathrm{D}_{\mathrm{o}}$ to 1.1 
a

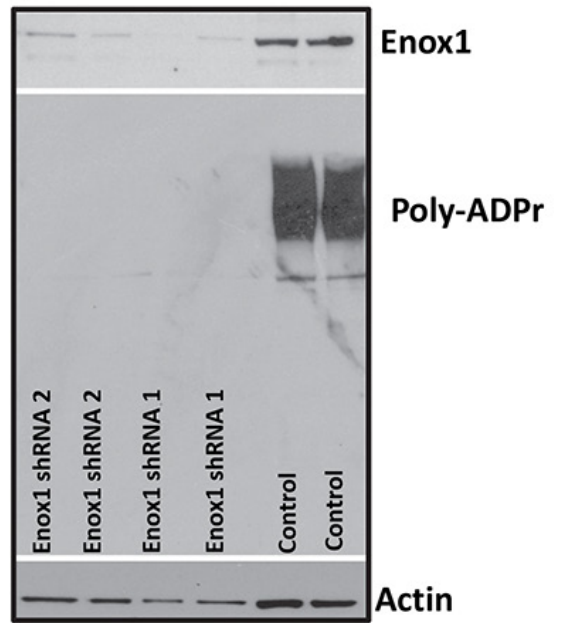

b

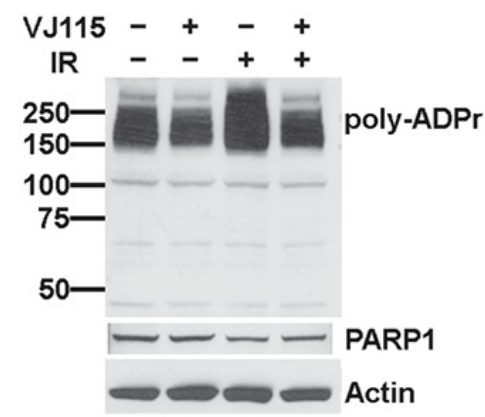

C

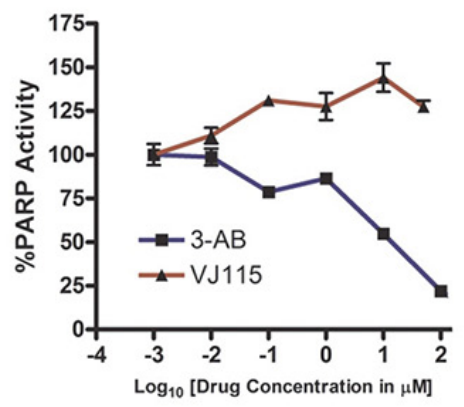

Figure 1: Targeting Enox1 inhibits PARP1 activity. a. Poly(ADP-ribosyl)ation. HUVECs were transduced with retrovirus expressing scrambled, non-targeted shRNA or Enox1 shRNA. Poly(ADP-ribose) (Poly-ADPr) addition was measured by immunoblot using an antibody directed against Poly-ADPr. The immunoblot illustrates addition of Poly-ADPr primarily to PARP1. b. HUVECs were exposed to $50 \mu \mathrm{M}$ VJ115 for $3 \mathrm{hrs}$, irradiated with (4 Gy), and then immediately processed for immunoblotting using an antibody directed against Poly-ADPr. The immunoblot illustrates addition of Poly-ADPr primarily to PARP1 c. VJ115 does not directly inhibit PARP1 activity. Purified recombinant PARP1 was exposed to varying concentrations of VJ115 or 3-AB. Enzyme activity was quantified using the Trevigen HT PARP assay kit according to the manufacturer's instructions.

a

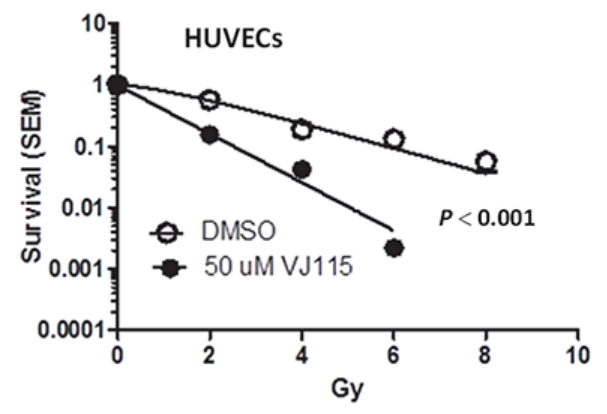

b

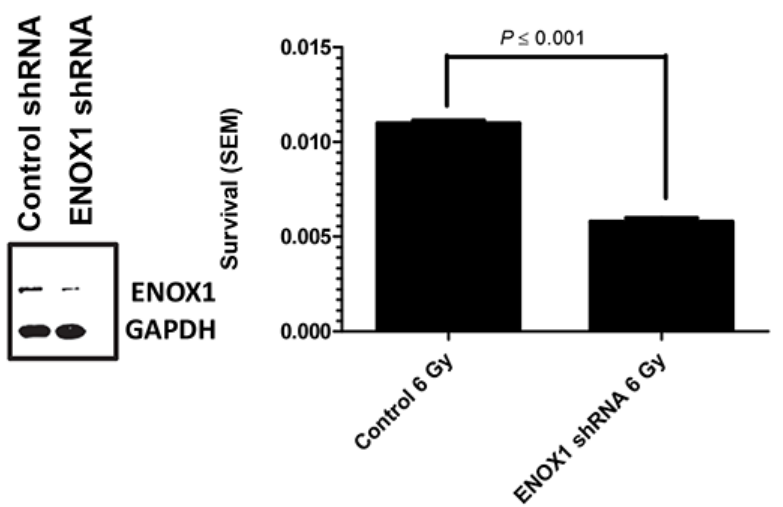

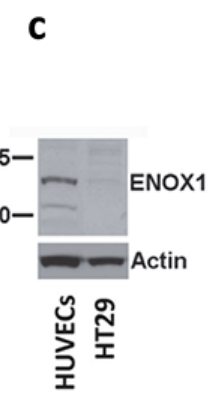

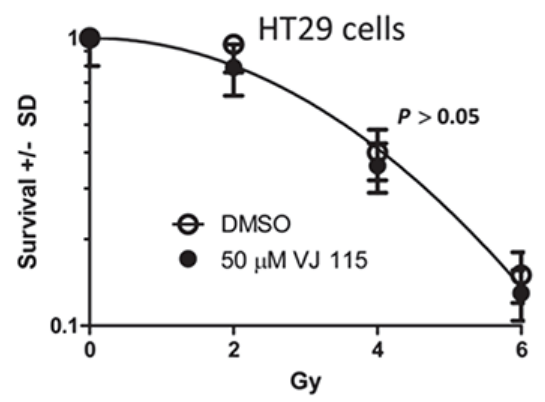

Figure 2: VJ115 radiosensitizes HUVECs. a. Cell survival curves for HUVECs cultured overnight on $0.1 \%$ gelatin-coated dishes, exposed to $50 \mu \mathrm{M} \mathrm{VJ115}$ or solvent control (DMSO/PBS) for $6 \mathrm{hrs}$, washed extensively and incubated for up to 3 weeks in colony formation assays. Cells were irradiated with ${ }^{137} \mathrm{Cs}$ in the middle of the drug exposure. b. Cell survival of HUVECs transduced with retrovirus expressing scrambled, non-targeted shRNA or Enox1 shRNA. Forty-eight hrs later cells were either immunoblotted for Enox1 or irradiated with 6 Gy and subjected to a colony formation assay. c. HT-29 cells are not radiosensitized by VJ115. Immunoblot illustrating Enox 1 expression in HUVECs but not in HT29 cells. HT29 cells were exposed to $50 \mu \mathrm{M}$ VJ115 or solvent control (DMSO/PBS) for 6 hrs, washed extensively and incubated for up to 3 weeks in colony formation assays. Cells were irradiated with ${ }^{137} \mathrm{Cs}$ in the middle of the drug exposure. 
and $\mathrm{n}$ to $1.0,(P<0.0001$, extra sum of squares $\mathrm{F}$ test $)$. Human microvascular endothelial cells (HMVECs) were also exposed to VJ115 and the resulting survival curves were fit to the equation $\left.S=1-\left(1-e^{-D / D o}\right)\right)^{n}$, Supplementary Figure S1. Inhibition of Enox1 in HMVECs did not affect the $\mathrm{D}_{\mathrm{o}}$ but resulted in a statistically significant reduction in (n), from a value of 6.0 to $2.0(P=0.032$, Supplementary Figure S1). Defective repair of DNA DSBs is reflected by decreases in $\mathrm{D}_{\mathrm{o}}$ [16] and/or decreases in $\mathrm{n}$ [13]. Thus, in two endothelial cell lines pharmacological targeting of Enox 1 produced statistically significant radiosensitization. To confirm that loss of Enox 1 can radiosensitize endothelial cells, HUVECs were transduced with retrovirus expressing either scrambled, control shRNA or Enox1 shRNA. RNAimediated suppression of Enox1 was found to radiosensitize HUVECs $(P<0.001$, Figure $2 \mathrm{~b})$. However, the radiation response of HT-29 cells, which do not express ENOX1 (Figure 2c), is independent of VJ115 $(P>0.05)$, suggesting that off target effects are minimal with regard to $\mathrm{VJ} 115$ -mediated radiation sensitization.
Although we have observed congruence between RNAi approaches and small molecule inhibition with regard to inhibiting angiogenesis and radiation sensitization, the remaining experiments focused on the small molecule inhibitor VJ115 in order to model preclinical xenograft studies where pharmacological targeting inhibits activity but does not cause loss of enzyme.

Impaired DNA double strand break repair represents a fundamental defect responsible for radiationinduced cell death [17]. Neutral comet assays are a well characterized and sensitive methodology for analyzing repair of DNA DSBs on a single cell basis [18]. Thus, neutral comet assays were employed to determine if Enox1-mediated radiosensitization was a consequence of repair defects. Analysis of comet tails (examples can be found in Supplementary Figure S2a) revealed that VJ115mediated targeting of Enox 1 in HUVECs did not affect the number of DNA DSBs generated during $\gamma$-irradiation performed at the non-permissive repair temperature of $4^{\circ} \mathrm{C}$ (Figure 3a). Repair was allowed to proceed after

a

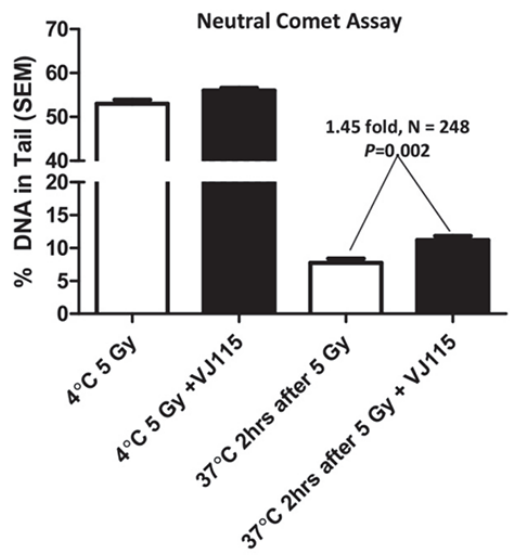

b $\quad \gamma \mathrm{H} 2 \mathrm{AX}$

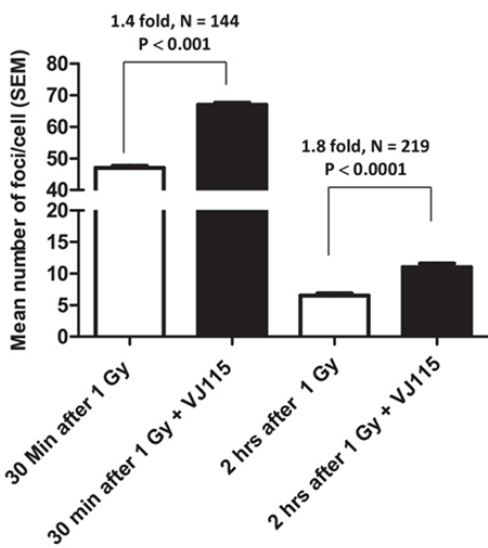

C

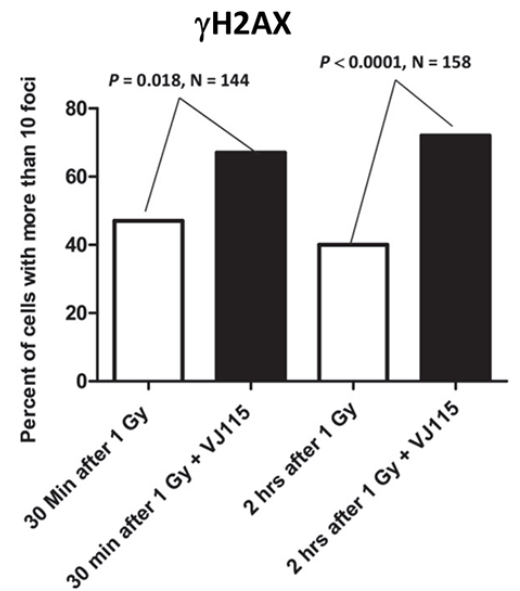

Figure 3: Inhibition of Enox1 impairs repair of DNA double strand breaks. a. Neutral comet assay. HUVECs were exposed to $50 \mu \mathrm{M} \mathrm{VJ} 115$ for $1.5 \mathrm{hrs}$, placed on ice for $10 \mathrm{~min}$, irradiated ( $5 \mathrm{~Gy}$ ) on ice and then immediately processed for neutral comet assay. Alternatively cells were irradiated and then incubated at $37^{\circ} \mathrm{C}$ for $2 \mathrm{hrs}$ prior to performing the neutral comet assay. b \& c. $\gamma \mathrm{H} 2 \mathrm{AX}$ foci formation in HUVECs. Cells were exposed to $50 \mu \mathrm{M} \mathrm{VJ} 115$ at $37^{\circ} \mathrm{C}$ for $1.5 \mathrm{hrs}$, administered $1 \mathrm{~Gy}$, incubated at $37^{\circ} \mathrm{C}$ for either 0.5 or $2 \mathrm{hrs}$, washed and fixed for immunofluorescence confocal microscopy. $\gamma \mathrm{H} 2 \mathrm{AX}$ foci per nuclei were quantified using Image $\mathrm{J}$ and are presented as mean number of foci per cell (b) or percent of cells with greater than 10 foci (c). 
irradiation by incubating cells at the repair permissive temperature of $37^{\circ} \mathrm{C}$. As shown in Figure 3a, repair of DNA DSBs was impaired in VJ115-treated cells. Two hours after irradiation we found that Enox 1 targeting suppressed repair by 1.45 fold, $P=0.002$.

$\gamma \mathrm{H} 2 \mathrm{AX}$ foci dynamics are a well-accepted surrogate for quantifying repair of DNA DSBs induced by ionizing radiation in single cells [19] (see Supplementary Figure S2b for examples). HUVECs were exposed to VJ115 for $1.5 \mathrm{hrs}$ prior to and for 0.5 or $2 \mathrm{hrs}$ after irradiation. Cells were fixed and nuclei imaged by immunofluorescence confocal microscopy. $\gamma \mathrm{H} 2 \mathrm{AX}$ foci were quantified on a per nucleus basis (Figure $3 \mathrm{~b}$ ). In addition the number of cells with more than 10 foci per nucleus was also quantified (Figure 3c). Non-irradiated cells contained 5 or fewer foci. Using both types of analysis we found that exposing HUVECs to pharmacological suppression of Enox1 resulted in statistically significant increases in the number of $\gamma \mathrm{H} 2 \mathrm{AX}$ foci per nucleus and the number of cells with more than 10 foci compared to solvent control (Figure $3 \mathrm{~b}$ and $3 \mathrm{c}$ ), consistent with results from the comet assay. Taken together we interpret these DNA damage assays to indicate that inhibition of Enox1 activity slowed the rate of DNA DSB repair, consistent with the increased radiosensitization observed in Figure 2.

During the repair process MDC1 is recruited to $\gamma \mathrm{H} 2 \mathrm{AX}$ foci, thus licensing recruitment of 53BP1 [20].
Interactions with $\mathrm{H} 4 \mathrm{~K} 20 \mathrm{me} 2$ act to retain 53BP1 foci at sites of damage [21], where it participates in regulation of the DSB repair decision tree [22]. Impaired recruitment of 53BP1 to sites of DSBs can increase radiosensitivity [23]. We quantified the number of 53BP1 foci and relative foci immunofluorescence (IF) intensity per nucleus in HUVECs exposed to solvent control or the small molecule VJ115. Non-irradiated cells harbored 2 or less foci per nucleus, independent of VJ115 exposure (representative images shown in Figure $4 \mathrm{a}$ and $4 \mathrm{~b}$ ). Thirty min after administration of 1 Gy of $\gamma$-rays, cells contained an average of $9 \pm 2$ (SEM) 53BP1 foci per nucleus independent of Enox1 targeting $(P=0.099)$. However, a Mann Whitney analysis revealed that pharmacological inhibition of Enox 1 activity was associated with a reduction in 53BP1 IF intensity per nucleus $(P=0.0128, \mathrm{~N}=224$, Figure $4 \mathrm{c}$, lower panel). In order to better characterize this finding, the frequency of occurrence for each relative IF intensity value per nucleus was tabulated (Figure 4c, lower panel). The frequency distribution analysis indicated that there were 2 times more cells with IF values of 4.0 or less in irradiated cells exposed to VJ115 compared to irradiated cells exposed to solvent control $(P=0.023$, Fisher' exact test). We interpret these data to indicate that inhibiting Enox 1 activity does not stop recruitment of 53BP1 to DNA DSB repair foci, but the amount of 53BP1 recruited to foci is significantly diminished.
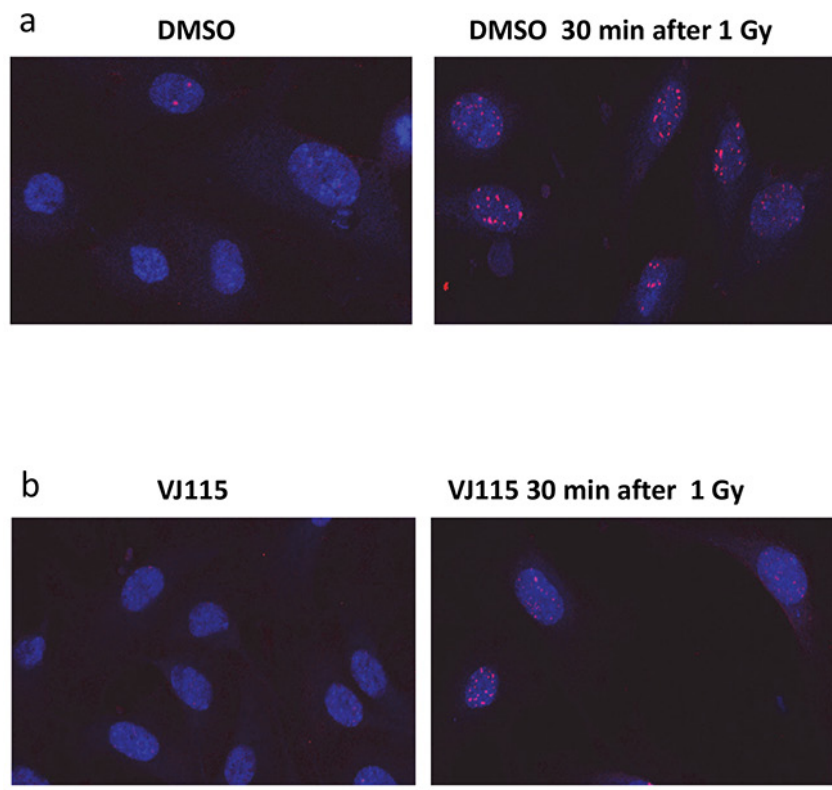

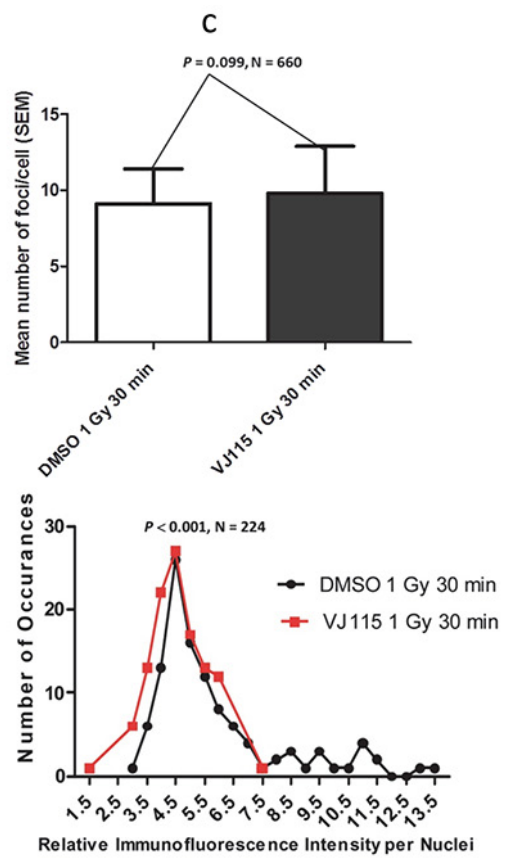

Figure 4: Exposure to VJ115 reduces 53BP1 accumulation at sites of DNA double strand breaks. HUVECs were exposed to DMSO, solvent control a. or $50 \mu \mathrm{M} \mathrm{VJ115} \mathrm{b.} \mathrm{for} 1.5 \mathrm{hrs}$ at $37^{\circ} \mathrm{C}$, administered 0 or $1 \mathrm{~Gy}$, incubated at $37^{\circ} \mathrm{C}$ for $0.5 \mathrm{hrs}$, washed and fixed for immunofluorescence confocal microscopy. The number of 53BP1 foci per nuclei was quantified using ImageJ and is presented as mean number of foci per cell or as the relative immunofluorescence intensity per nucleus as a function of the number of occurrences (panel c). Relative immunofluorescence intensity per nucleus represents mean 53BP1 foci intensity per nucleus ( $\mathrm{N}=112$ for DMSO control and $\mathrm{N}=112$ for $\mathrm{VJ} 115$ ). 


\section{Targeting Enox1 in tumor stroma during fractionated irradiation}

We have determined that HT-29 human colorectal adenocarcinoma cells are not radiosensitized by exposure to VJ115 (Figure 2c), whereas endothelial cells are (Figure 2b). This differential radiation response provided an opportunity to address a fundamental question: whether radiation sensitization of tumor stroma synergistically contributes to tumor control. Two experimental approaches were used to address this question.

For 4 consecutive days HT-29 xenograft-bearing mice were injected i.p. with DMSO or $40 \mathrm{mg} / \mathrm{kg}$ VJ115. Thirty min after injection tumors (approximately 150 $\mathrm{mm}^{3}$ ) were administered either 0 or 2 Gy. On the 5th day mice were injected i.p. with $60 \mathrm{mg} / \mathrm{kg}$ pimonidazole and then euthanized $60 \mathrm{~min}$ later. Tumors were excised, formalin fixed, paraffin embedded, and immunostained with antibody to Enox1, VE-Cadherin or pimonidazole. Confocal microscopy was used to image Enox1 and VECadherin immunostaining (Figure 5a), which is reported relative to DAPI staining (ie, on a per cell basis). We found that 4 daily injections of VJ115 did not affect expression of either Enox1 or VE-Cadherin compared to DMSO treatment $(P>0.05)$. Four daily 2 Gy fractions resulted in a statistically significant decrease in Enox1/VE-Cadherin immunostaining compared to DMSO treatment $(\cong 2$-fold, $P=0.0018)$. Four daily injections of VJ115 followed 30 min later by 2 Gy administered to the tumor resulted in a statistically significant decrease in Enox1/VE-Cadherin expression relative to radiation alone ( $\cong 5$-fold, $P=0.026$, Figure 5a). These data are interpreted to indicate that VJ115 significantly increased the effectiveness of the 2 Gy fractions.

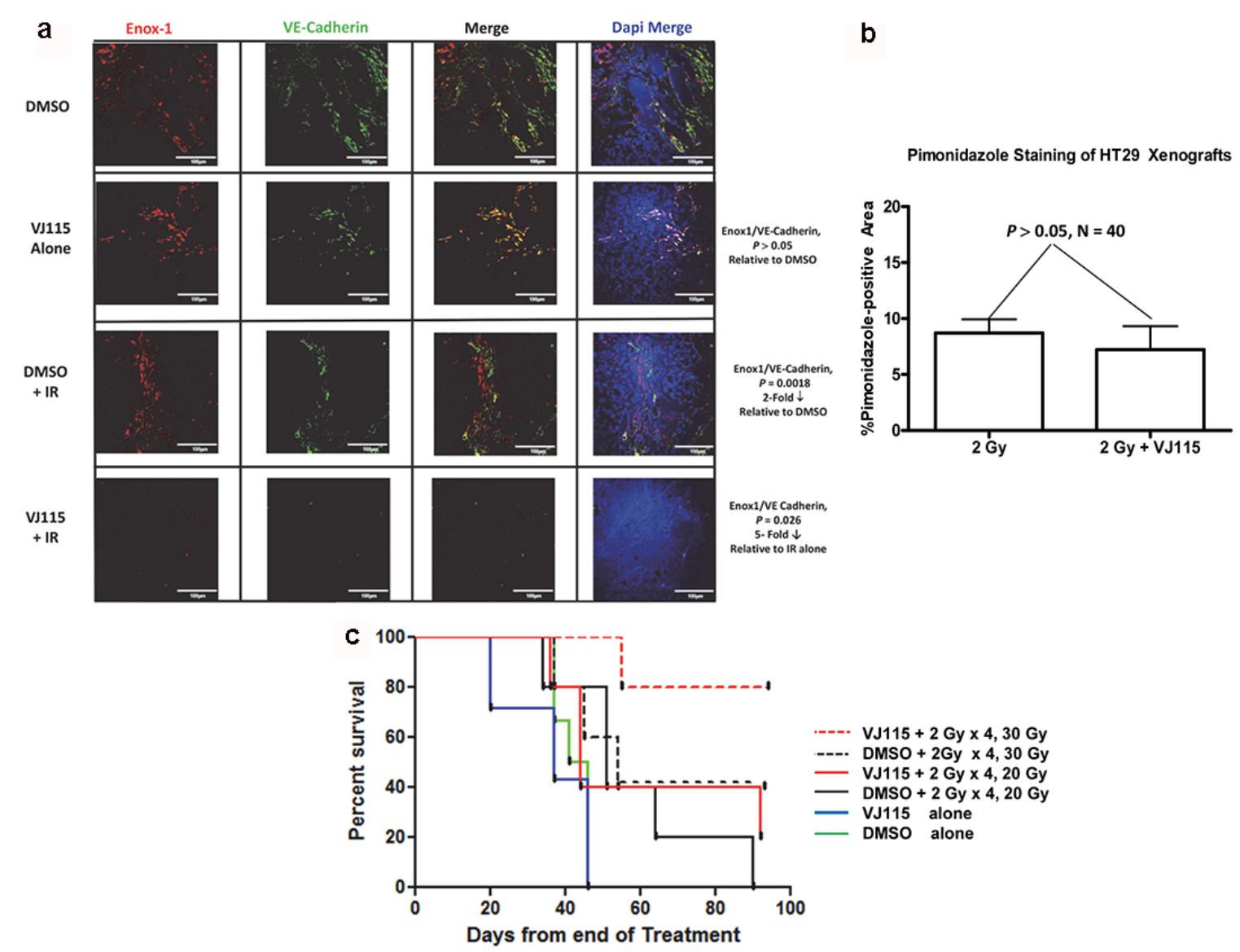

Figure 5: VJ115 radiosensitizes tumor vasculature and increases the survival of HT-29 tumor-bearing mice. a and b. For 4 consecutive days mice bearing HT29 s.c. xenografts were injected i.p. with $40 \mathrm{mg} / \mathrm{kg}$ VJ115 or DMSO. Thirty min later tumors were administered 0 or $2 \mathrm{~Gy}$ of $\mathrm{x}$-rays $(300 \mathrm{kVp} / 10 \mathrm{~mA}, 1.55 \mathrm{~Gy} / \mathrm{min})$. On the $5^{\text {th }}$ day mice were injected i.p. with pimonidazole and then euthanized $60 \mathrm{~min}$ later. Tumors were excised, formalin fixed, paraffin embedded and immunostained with antibodies to Enox1 (a), VECadherin (a), or Pimonidazole (b). Confocal microcopy was used to image Enox1 and VE-Cadhern at a magnification of 40x. White bars indicate $100 \mu \mathrm{m}$ distance. Pimonidazole whole slide imaging and quantification of immunostaining per tumor area were performed at a magnification of 20X by the Digital Histology Shared Resource at Vanderbilt University Medical Center. c. For 4 consecutive days mice bearing HT-29 s.c. xenografts were injected i.p. with $40 \mathrm{mg} / \mathrm{kg}$ VJ115 or DMSO. Thirty min later tumors were administered 0 or 2 Gy of X-rays $(300 \mathrm{kVp} / 10 \mathrm{~mA}, 1.55 \mathrm{~Gy} / \mathrm{min})$. On day 5 tumors were administered a single fraction of 20 or 30 Gy. Survival was quantified for up to 90 days. 
Pimonidazole whole slide imaging (Supplementary Figure S3) and quantification of immunostaining per tumor area were performed at a magnification of $20 \mathrm{X}$ by the Digital Histology Shared Resource at Vanderbilt University Medical Center (www.mc.vanderbilt.edu/ dhsr). An analysis indicated that the degree of tumor hypoxia was unaffected by administration of VJ115 alone. However, exposure to 4 daily 2 Gy fractions increased the degree of tumor hypoxia, consistent with the loss of tumor microvasculature observed in Figure 5a. Administration of VJ115 plus 2 Gy q.d. $x 4$ did not yield further increases in pimonidazole immunostaining (Figure $5 \mathrm{~b}, P>0.05, \mathrm{~N}=$ 6 fields per mouse, 5 mice per group). One interpretation for such a result is that VJ115-mediated radiosensitization occurred in areas that were already significantly hypoxic and the pimonidazole immunostaining assay was not sufficiently sensitive to detect further increases in hypoxia.

We next addressed the question of whether VJ115 targeting of Enox1 would affect tumor control. For 4 consecutive days HT-29 xenograft-bearing mice were injected i.p. with either DMSO or $40 \mathrm{mg} / \mathrm{kg}$ VJ115. Thirty min after injection tumors (approximately $150 \mathrm{~mm}^{3}$ ) were administered $2 \mathrm{~Gy}$. On the $5^{\text {th }}$ day tumors were administered either a 20 or 30 Gy top-up dose in the absence of VJ115 (Figure 5c). The time between administration of VJ115 and the 2 Gy fraction was based on the pharmacokinetic profile of VJ115 $\left(\mathrm{T}_{1 / 2}\right.$ in plasma $=30 \mathrm{~min}$ [24]).

Survival of tumor-bearing mice was quantified 90 days after the last treatment. No tumor-bearing mouse administered DMSO or VJ115 and sham irradiation remained alive 60 days after treatment (solid green or blue lines, Figure 5c). The short pharmacokinetic halflife of VJ115 may explain why 4 daily i.p. injections of VJ115 did not affect survival. Survival at 90 days was $20 \%$ or less for mice administered DMSO or VJ115, 2 Gy x 4 q.d., and a top-up dose of 20 Gy (solid black and red lines). However, $80 \%$ of tumor-bearing mice were alive at 90 days when they received VJ115 plus 2 Gy for 4 consecutive days followed by a top-up dose of 30 Gy (red dashed line, Figure 5c). The Bliss independence formula $\left[\mathrm{E}_{\mathrm{IND}}=\left(\mathrm{E}_{\mathrm{A}}+\mathrm{E}_{\mathrm{B}}\right)-\left(\mathrm{E}_{\mathrm{A}} \mathrm{x} \mathrm{E}_{\mathrm{B}}\right)\right.$ and $\Delta \mathrm{E}=\mathrm{E}_{\mathrm{OBS}}-\mathrm{E}_{\mathrm{IND}}$, where $E_{A}$ is the effect of treatment $A$ and $E_{B}$ is the effect of treatment B] [25] was used to determine if this increase in survival was due to the two treatments being synergistic. The analysis indicated that $\Delta \mathrm{E}$ was greater than $0(P=$ 0.03 , Fishers exact test). Thus the VJ115-mediated effect was considered synergistic with irradiation. We interpret these results to indicate that pharmacological targeting of Enox 1 in tumor stroma inflicted a significant degree of radiation-induced damage to tumor stroma that contributed to radiation-induced tumor control.

\section{DISCUSSION}

The NADH oxidase, Enox1, participates in NADH/ NAD + cell homeostasis [5]. Inhibition of Enox 1 activity results in a profound elevation of intracellular NADH [6, 11], suppression of vascular development in zebrafish models of embryogenesis [6], inhibition of endothelial cell migration, abrogation of the ability to form tubulelike structures [8], and suppression of neoangiogenesis in dorsal skin fold vascular window chamber models [8]. Inhibiting Enox 1 activity also enhances radiation-induced endothelial cell cytotoxicity, although the mechanism for this is undefined [8].

In the present study we demonstrate a direct link between Enox1 activity, repair of DNA damage, and radiation sensitivity. Inhibition of Enox1 activity diminished the repair of DNA DSBs, which translated into increased radiosensitization. When modeling cell survival curves using the equation $\mathrm{S}=1-\left(1-\mathrm{e}^{-\mathrm{D} / \mathrm{Do})}\right)^{\mathrm{n}}$, the term $\mathrm{n}$ is a reflection of the ability to repair DNA damage [13]. Pharmacological targeting of Enox1 in both HUVECs and HMVECs produced a statistically significant decrease in $\mathrm{n}$, which can be interpreted as a loss of DNA repair capacity. This concept was validated by quantifying $\gamma \mathrm{H} 2 \mathrm{AX}$ foci formation and carrying out neutral comet assays. While the mechanism responsible for loss of DNA repair capacity was not addressed in this study, we found that the amount of 53BP1 recruited to sites of DNA damage was significantly diminished. One possibility that could contribute to diminished 53PB1 accumulation and increased radiation sensitivity involves NAD+-PARP1-dependent generation of poly(ADPribose) (PAR) chains on histones. H4K20 methylation is required for recruitment of 53BP1 to sites of DNA DSBs [26]. H4K20 methylation requires mono ubiquitination of H4K91 by BBAP E3 and BAL1. PARP1 activity mediates BAL1-BBAP-mediated ubiquitinylation[27], which in turn regulates accumulation of 53BP1 to sites of DNA damage $[28,29]$. Loss of PARP1 activity results in a failure to recruit BBAP to sites of damage, decreased 53BP1 accumulation, failure to resolve DNA DSBs, as measured by comet tail moment, and increased sensitivity to ionizing radiation $[28,29]$. Testing of this hypothesis however, is beyond the scope of this investigation.

Previous studies have shown that small molecule inhibition of Enox 1 in irradiated allograft and xenograft tumors significantly reduced tumor microvascular density and increased radiation-induced tumor growth delay [8]; however, it was not known if targeting Enox 1 in stroma could extend the life of tumor-bearing mice. Therefore, we focused on the question of whether concurrent $\mathrm{x}$-irradiation and pharmacological inhibition of Enox 1 in tumor stroma could increase the survival of HT-29 tumor-bearing mice. The HT29 tumor model was used because these cells do not express Enox1 and they are not radiosensitized by pharmacological inhibition of Enox1. Thus, VJ115-mediated radiosensitization would be stroma-specific.

The majority of studies that have addressed the issue of whether targeting tumor stroma would increase tumor 
radiosensitivity have focused on angiogenic inhibitors and have used tumor growth delay as an endpoint [30 33]. While a combination of antiangiogenic treatment and irradiation produced significantly more growth delay than either modality by itself, it is hard to determine if the results are due to additivity or synergism. For example, Kozin et al [30] performed growth delay on two human xenografts using a VEGFR2 antibody. Because tumor grow delay studies do not quantify survival of tumor-bearing mice Tumor Control Dose (TCD) experiments were also undertaken. Tumor Control Dose (TCD)represents a dose of ionizing radiation needed to produce continuous control of irradiated tumors over a defined experimental interval, usually 90 or more days. Thus, a $\mathrm{TCD}_{50}$ value, for example, indicates that $50 \%$ of the tumor-bearing mice survived for a minimum of 90 days without tumor progression. Both the tumor growth delay experiments and the TCD analysis indicated that VEGFR2 antibody plus irradiation produced significant growth delay and decreased TCD values compared to either modality alone. However, Kozin and colleagues interpreted these results to be due to additive not synergistic effects, thus indicating that targeting of the VEGF/VEGFR pathway is not radiosensitizing.

Mice harboring targeted disruption of genes critical for repair of DNA damage also have been used to address the role of tumor stroma. Ogawa et al [34] used repair-proficient tumor cells implanted in wild type or SCID mice. Tumor growth delay induced by irradiation was significantly enhanced in SCID mice compared to tumor-bearing wild type mouse, suggesting that the stroma represents an important factor. GarciaBarros and colleagues [35] used acid sphingomyelinase null and wild type mice to address the role of the tumor microenvironment. Endothelial cells in acid sphingomyelinase null mice are radiation resistant compared to sphingomyelinase proficient cells [35]. When wild type and acid sphingomyelinase null mice were implanted with repair proficient tumor cells radiationinduced tumor growth delay was found to be profoundly influenced by the endothelial radiation response [35]. However, alternative results were obtained from TCD experiments. Repair-proficient syngeneic and xenograft tumors were implanted into the hind legs of SCID or nude mice. Tumor-bearing legs were made totally anoxic/ hypoxic by clamping the legs for $5 \mathrm{~min}$ and irradiating under clamped conditions. Quantification of TCD values led Budach et al [36] and $\mathrm{Li}$ et al [37] to conclude that the number of tumor progenitor cells and their intrinsic radiosensitivity were the major determinants of local tumor control, with little contribution from host stroma. However, a caveat to this interpretation is the potentially confounding effect of extreme hypoxia, a consequence of clamping, on DNA repair capacity. Extreme hypoxia has the potential to significantly impair the DNA damage response [38]. Thus, one cannot rule out an alternative interpretation that hypoxia incapacitated repair pathways in tumor stroma and negated the difference in DNA repair potential expected between SCID and nude mice.

In the experiments undertaken in this investigation we used the small molecule inhibitor VJ115 that targets Enox 1 in the tumor vasculature but does not radiosensitize HT-29 tumor cells. We cannot, however, rule out radiosensitization of other components of the tumor microenvironment beyond the vasculature. We found that addition of the inhibitor to four daily 2 Gy factions of x-rays significantly decreased tumor vasculature and increased the survival of tumor-bearing mice compared to mice injected with DMSO control when the damage produced by the fractionated radiation was amplified by a 30 Gy top-up dose. It is important to note that we cannot rule out the possibility that 4 days of VJ115 administration by itself sensitized the tumor endothelial cells to the 30 Gy top-up dose and thus also contributed to the survival response.

Use of top-up doses is primarily a radiation biology laboratory method to quantitatively analyze the effects produced by low doses per fraction without the need to administer large numbers of fractions $[9,10]$. We used this technique as a tool to address the central question of whether radiosensitization of tumor stroma would improve the ability of radiotherapy to cure tumors. While there is not a direct clinical correlate, a clinical analogy would be the use of a boost dose in patients with early stage breast cancer who undergo breast conserving therapy. Despite a high cure rate, invasive recurrence and death may occur in case of insufficient local treatment [39, 40]. Following breast conserving surgery, patients are administered a course of fractionated radiotherapy followed by a boost dose. The purpose of the boost dose is to reduce the risk of local relapse $[40,41]$. Boost-induced normal tissue injury such as fibrosis represents a major limitation however. Ideally, one would like to administer a standard course of fractionated radiotherapy followed by a boost dose that controls local recurrence but does not promote normal tissue injury. We speculate that targeting tumor vasculature might provide significant local tumor control, allowing a boost dose to be decreased in order to spare local tissue from injury.

In summary, the data presented herein suggests that Enox1 regulation of tumor stroma radiosensitivity via NADH/NAD cellular metabolism can contribute significantly to tumor control and survival and identifies Enox1 as a potential therapeutic target.

\section{MATERIALS AND METHODS}

\section{Antibodies}

The following antibodies were used: anti-PAR was obtained from Tulip Biolabs catalog \#1020; anti- $\gamma \mathrm{H} 2 \mathrm{AX}$ was obtained from Millipore catalog \#05-636; anti-53BP1 
was obtained from Novus Biologicals catalog \#304; Antipimonidazole mouse IgG1 monoclonal antibody (MAb1) was obtained from Hypoxyprobe, Inc. Anti-Enox1 rabbit polyclonal antibody was custom made by Covance, Inc [11]; Anti-VE-Cadherin mouse monoclonal IgG1 antibody catalog \#sc-9989 was obtained from Santa Cruz Biotechnology, Inc; Secondary antibodies Alexa 568 antirabbit goat polyclonal catalog \#A11011 and Alexa 647 anti-mouse donkey polyclonal catalog \#A31571 were both obtained from Life Technologies, Inc.

\section{Cell culture}

HUVECs, and HT-29 cells were obtained from ATCC and were cultured according to ATCC directions. HMVECs were a gracious gift from DE Hallahan, Washington University School of Medicine. Colony formation assays were conducted as described previously [42].

\section{PARP1 activity}

In vitro PARP1 activity Trevigen (Cat\# 4676-096K) was measured using the manufacturer's directions.

\section{HT-29 xenografts}

These studies were performed under the Guidelines for the Care and Use of Research Animals, Vanderbilt University Animal Studies Committee. Hind limbs of homozygous nu/ nu athymic nude mice, approximately 6-8 weeks of age, were subcutaneously implanted with 2 x 10 $0^{6}$ HT-29 human colorectal cancer cells. HT-29 tumors were allowed to reach a volume of approximately $150 \mathrm{~mm}^{3}$. For HT-29 tumors, 5 animals per group were used. Mice received daily i.p. injections of DMSO $(25 \mu \mathrm{l})$ or $40 \mathrm{mg} / \mathrm{kg}$ of VJ115 in DMSO $(25 \mu \mathrm{l})$ for 4 consecutive days, followed $30 \mathrm{~min}$ later by 0 or 2 Gy of x-rays (300 kVp/10 mA). During irradiation, mice were shielded such that only the tumors were irradiated. Tumors in the survival experiment were measured prior to initiation of treatment using digital calipers to ensure that there were comparable sizes between groups at the start. Tumors were deemed not cured if they exhibited any gross growth after 1 week following the top-up dose.

\section{Immunofluorescence staining and quantification of tumor sections}

Tumors were excised, formalin-fixed and paraffin embedded. Tissue sections were cut at $5 \mu \mathrm{m}$ thickness and deparaffinized, permeabilized, and immunostained with Enox1 1:1,1000 (Alexa 568, red) and VE-Cadherin 1:200 (Alexa 647, green). For Enox1 and VE-Cadherin immunofluorescence confocal microscopy imaging was performed on 5 mice per group, 3 fields per mouse at a magnification of $40 \mathrm{X}$ at $0.66 \mu \mathrm{M}$ optical thickness, obtained using an Olympus FV-1000 inverted confocal microscope provided by the Cell Imaging Shared Resource at Vanderbilt University Medical Center. Quantification of immunofluorescence intensity was performed on ImageJ and corrected by DAPI staining on a per cell basis.

\section{Pimonidazole staining of tumor hypoxia}

Pimonidazole was obtained from the Hypoxyprobe-1 Kit and used according the manufacturer's directions. Five mice per group and 6 fields per mouse were quantified following Pimonidazole immunohistochemistry.

\section{ACKNOWLEDGMENTS}

This research was supported in part by an ABR Holman Research Pathway Fellowship (CAS), NCI LRP Extramural Research Contract (CAS), RO1 CA140409, and Vanderbilt-Ingram Cancer Center grant P30 CA68484.

\section{CONFLICTS OF INTEREST}

The authors declare no conflicts of interest.

\section{REFERENCES}

1. https://www.cancer.gov/about-cancer/treatment/types/ radiation-therapy/radiation-fact-sheet NCI 2016.

2. Early Breast Cancer Trialists' Collaborative G, Darby S, McGale P, Correa C, Taylor C, Arriagada R, Clarke M, Cutter D, Davies C, Ewertz M, Godwin J, Gray R, Pierce L, et al. Effect of radiotherapy after breast-conserving surgery on 10-year recurrence and 15-year breast cancer death: meta-analysis of individual patient data for 10,801 women in 17 randomised trials. Lancet. 2011; 378: 1707-16. doi: 10.1016/S0140-6736(11)61629-2.

3. Bosset JF, Collette L, Calais G, Mineur L, Maingon P, Radosevic-Jelic L, Daban A, Bardet E, Beny A, Ollier JC, Trial ERG. Chemotherapy with preoperative radiotherapy in rectal cancer. N Engl J Med. 2006; 355: 1114-23. doi: 10.1056/NEJMoa060829.

4. Yu TK, Bhosale PR, Crane CH, Iyer RB, Skibber JM, Rodriguez-Bigas MA, Feig BW, Chang GJ, Eng C, Wolff RA, Janjan NA, Delclos ME, Krishnan S, et al. Patterns of locoregional recurrence after surgery and radiotherapy or chemoradiation for rectal cancer. Int J Radiat Oncol Biol Phys. 2008; 71: 1175-80. doi: 10.1016/j.ijrobp.2007.11.018.

5. Morre DJ. (1998). NADH oxidase: a multifunctional ectroprotein of the eukaryotic cell surface. In: H. Asard ABr, R.J. Caubergs (Eds.),, ed. Plasma Membrane Redox Systems and Their Role in Biological Stress and Disease,. (Dordrecht, The Netherlands: Kluwer Academic Publishers,), pp. pp 121-56.

6. Venkateswaran A, Sekhar KR, Levic DS, Melville DB, Clark TA, Rybski WM, Walsh AJ, Skala MC, Crooks PA, Knapik EW, Freeman ML. The NADH oxidase ENOX1, a critical mediator of endothelial cell radiosensitization, is 
crucial for vascular development. Cancer Res. 2014; 74: 38-43.doi: 10.1158/0008-5472.CAN-13-1981.

7. Uhlen M, Fagerberg L, Hallstrom BM, Lindskog C, Oksvold P, Mardinoglu A, Sivertsson A, Kampf C, Sjostedt E, Asplund A, Olsson I, Edlund K, Lundberg E, et al. Proteomics. Tissuebased map of the human proteome. Science. 2015; 347: 1260419. doi: 10.1126/science.1260419.

8. Geng L, Rachakonda G, Morre DJ, Morre DM, Crooks PA, Sonar VN, Roti JL, Rogers BE, Greco S, Ye F, Salleng KJ, Sasi S, Freeman ML, et al. Indolyl-quinuclidinols inhibit ENOX activity and endothelial cell morphogenesis while enhancing radiation-mediated control of tumor vasculature. FASEB J. 2009; 23: 2986-95. doi: 10.1096/fj.09-130005.

9. Joiner MC. The design and interpretation of 'top-up' experiments to investigate the effects of low radiation doses. Int J Radiat Biol Relat Stud Phys Chem Med. 1987; 51: 115-30.

10. Joiner MC, Denekamp J, Maughan RL. The use of 'top-up' experiments to investigate the effect of very small doses per fraction in mouse skin. Int J Radiat Biol Relat Stud Phys Chem Med. 1986; 49: 565-80.

11. Venkateswaran A, Friedman DB, Walsh AJ, Skala MC, Sasi S, Rachakonda G, Crooks PA, Freeman ML, Sekhar KR. The novel antiangiogenic VJ115 inhibits the NADH oxidase ENOX1 and cytoskeleton-remodeling proteins. Invest New Drugs. 2013; 31: 535-44. doi: 10.1007/s10637-012-9884-9.

12. Feng FY, Speers C, Liu M, Jackson WC, Moon D, Rinkinen J, Wilder-Romans K, Jagsi R, Pierce LJ. Targeted radiosensitization with PARP1 inhibition: optimization of therapy and identification of biomarkers of response in breast cancer. Breast Cancer Res Treat. 2014; 147: 81-94. doi: 10.1007/s10549-014-3085-5.

13. Hall EJ, Giaccia AJ. (2012). Radiobiology for the Radiologist: Wolters Kluwer/Lippincott Williams \& Wilkins).

14. Sorci L, Ruggieri S, Raffaelli N. NAD homeostasis in the bacterial response to DNA/RNA damage. DNA Repair (Amst). 2014; 23: 17-26. 10.1016/j.dnarep.2014.07.014.

15. Tubiana M DJ, and Wambersie A, . (1990). Introduction to Radiobiology. (London: Taylor \& Francis).

16. Kirchgessner CU, Patil CK, Evans JW, Cuomo CA, Fried LM, Carter T, Oettinger MA, Brown JM. DNA-dependent kinase (p350) as a candidate gene for the murine SCID defect. Science. 1995; 267: 1178-83.

17. Biedermann KA, Sun JR, Giaccia AJ, Tosto LM, Brown JM. scid mutation in mice confers hypersensitivity to ionizing radiation and a deficiency in DNA double-strand break repair. Proc Natl Acad Sci U S A. 1991; 88: 1394-7. PMCID 51024.

18. Olive PL. Impact of the comet assay in radiobiology. Mutat Res. 2009; 681: 13-23. doi: 10.1016/j.mrrev.2007.11.001.

19. Borras M, Armengol G, De Cabo M, Barquinero JF, Barrios L. Comparison of methods to quantify histone H2AX phosphorylation and its usefulness for prediction of radiosensitivity. Int J Radiat Biol. 2015; 91: 915-24.doi: 10.3109/09553002.2015.1101501.
20. Xie A, Hartlerode A, Stucki M, Odate S, Puget N, Kwok A, Nagaraju G, Yan C, Alt FW, Chen J, Jackson SP, Scully R. Distinct roles of chromatin-associated proteins MDC1 and 53BP1 in mammalian double-strand break repair. Mol Cell. 2007; 28: 1045-57. doi: 10.1016/j.molcel.2007.12.005.

21. Daley JM, Sung P. 53BP1, BRCA1, and the choice between recombination and end joining at DNA double-strand breaks. Mol Cell Biol. 2014; 34: 1380-8. doi: 10.1128/ MCB.01639-13.

22. Aparicio T, Baer R, Gautier J. DNA double-strand break repair pathway choice and cancer. DNA Repair (Amst). 2014; 19: 169-75. doi: 10.1016/j.dnarep.2014.03.014.

23. Chapman JR, Barral P, Vannier JB, Borel V, Steger M, Tomas-Loba A, Sartori AA, Adams IR, Batista FD, Boulton SJ. RIF1 is essential for 53BP1-dependent nonhomologous end joining and suppression of DNA double-strand break resection. Mol Cell. 2013; 49: 858-71. doi: 10.1016/j. molcel.2013.01.002.

24. Al-Ghananeem AM, Albayati ZF, Malkawi A, Sonar VN, Freeman ML, Crooks PA. A pharmacokinetic study on Z-(+/-) -2-(1-benzylindole-3-yl-methylene)azabicyclo[2.2.2] octane-3-ol; a novel radio-sensitization agent. Cancer Chemother Pharmacol. 2007; 60: 915-9.

25. Kyula JN, Khan AA, Mansfield D, Karapanagiotou EM, McLaughlin M, Roulstone V, Zaidi S, Pencavel T, Touchefeu Y, Seth R, Chen NG, Yu YA, Zhang Q, et al. Synergistic cytotoxicity of radiation and oncolytic Lister strain vaccinia in (V600D/E)BRAF mutant melanoma depends on JNK and TNF-alpha signaling. Oncogene. 2014; 33: 1700-12. doi: 10.1038/onc.2013.112.

26. Botuyan MV, Lee J, Ward IM, Kim JE, Thompson JR, Chen J, Mer G. Structural basis for the methylation statespecific recognition of histone H4-K20 by 53BP1 and Crb2 in DNA repair. Cell. 2006; 127: 1361-73. doi: 10.1016/j. cell.2006.10.043.

27. Elea Heberle J-CA, Giuditta Illuzzi, Francoise Dantzer and Valerie Schreiber. (2015). PARP Inhibitors for Cancer Therapy: Humana Press/Springer).

28. Yan Q, Dutt S, Xu R, Graves K, Juszczynski P, Manis JP, Shipp MA. BBAP monoubiquitylates histone H4 at lysine 91 and selectively modulates the DNA damage response. Mol Cell. 2009; 36: 110-20. doi: 10.1016/j.molcel.2009.08.019.

29. Yan Q, Xu R, Zhu L, Cheng X, Wang Z, Manis J, Shipp MA. BAL1 and its partner E3 ligase, BBAP, link Poly(ADPribose) activation, ubiquitylation, and double-strand DNA repair independent of ATM, MDC1, and RNF8. Mol Cell Biol. 2013; 33: 845-57. doi: 10.1128/MCB.00990-12.

30. Kozin SV, Boucher Y, Hicklin DJ, Bohlen P, Jain RK, Suit HD. Vascular endothelial growth factor receptor-2-blocking antibody potentiates radiation-induced long-term control of human tumor xenografts. Cancer Res. 2001; 61: 39-44.

31. Rofstad EK, Henriksen K, Galappathi K, Mathiesen B. Antiangiogenic treatment with thrombospondin-1 enhances primary tumor radiation response and prevents growth of 
dormant pulmonary micrometastases after curative radiation therapy in human melanoma xenografts. Cancer Res. 2003; 63: 4055-61.

32. Williams KJ, Telfer BA, Shannon AM, Babur M, Stratford IJ, Wedge SR. Combining radiotherapy with AZD2171, a potent inhibitor of vascular endothelial growth factor signaling: pathophysiologic effects and therapeutic benefit. Mol Cancer Ther. 2007; 6: 599-606. doi: 10.1158/1535-7163.

33. Cao C, Albert JM, Geng L, Ivy PS, Sandler A, Johnson DH, Lu B. Vascular endothelial growth factor tyrosine kinase inhibitor AZD2171 and fractionated radiotherapy in mouse models of lung cancer. Cancer Res. 2006; 66: 11409-15. doi: 10.1158/0008-5472.

34. Ogawa K, Boucher Y, Kashiwagi S, Fukumura D, Chen D, Gerweck LE. Influence of tumor cell and stroma sensitivity on tumor response to radiation. Cancer Res. 2007; 67: 4016-21.

35. Garcia-Barros M, Paris F, Cordon-Cardo C, Lyden D, Rafii S, Haimovitz-Friedman A, Fuks Z, Kolesnick R. Tumor response to radiotherapy regulated by endothelial cell apoptosis. Science. 2003; 300: 1155-9.

36. Budach W, Taghian A, Freeman J, Gioioso D, Suit HD. Impact of stromal sensitivity on radiation response of tumors. J Natl Cancer Inst. 1993; 85: 988-93.

37. Li W, Huang P, Chen DJ, Gerweck LE. Determinates of tumor response to radiation: tumor cells, tumor stroma and permanent local control. Radiother Oncol. 2014; 113: 1469. doi: 10.1016/j.radonc.2014.09.006.
38. Koch CJ, Painter RB. The effect of extreme hypoxia on the repair of DNA single-strand breaks in mammalian cells. Radiat Res. 1975; 64: 256-69.

39. Sadek BT, Homayounfar G, Abi Raad RF, Niemierko A, Shenouda MN, Keruakous AR, Specht MC, Taghian AG. Is a higher boost dose of radiation necessary after breastconserving therapy for patients with breast cancer with final close or positive margins? Breast Cancer Res Treat. 2015; 154: 71-9. doi:10.1007/s10549-015-3579-9.

40. Clarke M, Collins R, Darby S, Davies C, Elphinstone P, Evans V, Godwin J, Gray R, Hicks C, James S, MacKinnon E, McGale P, McHugh T, et al. Effects of radiotherapy and of differences in the extent of surgery for early breast cancer on local recurrence and 15-year survival: an overview of the randomised trials. Lancet. 2005; 366: 2087-106. doi: 10.1016/S0140-6736(05)67887-7.

41. Bartelink H, Horiot JC, Poortmans PM, Struikmans H, Van den Bogaert W, Fourquet A, Jager JJ, Hoogenraad WJ, Oei SB, Warlam-Rodenhuis CC, Pierart M, Collette L. Impact of a higher radiation dose on local control and survival in breast-conserving therapy of early breast cancer: 10-year results of the randomized boost versus no boost EORTC 22881-10882 trial. J Clin Oncol. 2007; 25: 3259-65. doi: 10.1200/JCO.2007.11.4991.

42. Sekhar KR, Benamar M, Venkateswaran A, Sasi S, Penthala NR, Crooks PA, Hann SR, Geng L, Balusu R, Abbas T, Freeman ML. Targeting nucleophosmin 1 represents a rational strategy for radiation sensitization. Int $\mathrm{J}$ Radiat Oncol Biol Phys. 2014; 89: 1106-14. doi: 10.1016/j. ijrobp.2014.04.012. 